\title{
Percutaneous balloon dilatation of calcific aortic valve stenosis: anatomical and haemodynamic evaluation
}

\author{
P COMMEAU, G GROLLIER, E LAMY, J P FOUCAULT, C DURAND, G MAFFEI, \\ D MAIZA, A KHAYAT, J C POTIER
}

From the Services de Réanimation Cardiologique, de Cardiologie et de Chirurgie Cardio-vasculaire, CHU Côte de Nâcre, Caen, France

SUMMARY Two groups of elderly patients with calcified aortic stenosis were treated by balloon dilatation. In group 1, the valve was dilated just before surgical replacement of the valve. The valvar and annular changes occurring during dilatation were examined visually. In 20 of the 26 patients in this group there was no change. In the six remaining patients mobilisation of friable calcific deposits ( 1 case), slight tearing of the commissure ( 4 cases), or tearing of the aortic ring (1 case) were seen. Dilatation did not appear to alter valvar rigidity. In 14 patients (group 2) the haemodynamic gradient across the aortic valve was measured before and immediately after dilatation and one week after the procedure. Dilatation produced an immediate significant decrease of the aortic mean gradient and a significant increase of the aortic valve area. Eight days later the mean gradient had increased and the aortic valve area had decreased. Nevertheless there was a significant difference between the initial gradient and the gradient eight days after dilatation. The initial aortic valve area was also significantly larger than the area eight days after dilatation. The aortic valve gradient rose significantly in the eight days after dilatation and at follow up the gradients were those of severe aortic stenosis.

Percutaneous transluminal balloon dilatation is increasingly used as an alternative to operation to treat arterial stenosis in peripheral, renal, coronary, and supra-aortic circulations. ${ }^{1-4}$ There is considerable interest in the long term results of this procedure. ${ }^{1-4}$ Percutaneous balloon dilatation was successful in children with stenosis of the pulmonary and aortic valves, ${ }^{56}$ and transseptal balloon dilatation of the mitral valve was successful in adults. ${ }^{7-9}$ More recently Cribier et al and McKay et al attempted percutaneous balloon dilatation of severe calcified aortic stenosis in elderly patients, ${ }^{1011}$ and the use of this procedure seems to have expanded considerably in the last few months in France where more than 150 patients have undergone percutaneous balloon dilatation of the aortic valve.

We have examined the valvar and annular changes caused by dilatation immediately before the affected valve was replaced in one set of patients and the haemodynamic gradients before and immediately after dilatation and one week after the procedure in another set of patients.

Requests for reprints to Dr P Commeau, Service de Cardiologie, CHU Côte de Nâcre, 14040 Caen Cedex, France.

Accepted for publication 14 July 1987

\section{Patients and methods}

GROUP 1

Table 1 shows the haemodynamic and anatomical findings in 26 patients who had aortic valve replacement because of a severely calcified aortic stenosis. The procedure was performed as follows: after an extracorporeal circulation and cardioplegia had been established, a transverse aortotomy permitted the examination of the aortic valve, commissures, aortic wall, and calcified deposits. Then a $9 \mathrm{Fr}$ balloon catheter (18 or $20 \mathrm{~mm}$ diameter when inflated) was introduced through the aortic valve (fig 1). The balloon was inflated several times with $10 \mathrm{ml}$ of saline solution up to a 5 to 6 atmospheres. Then the valve was examined again for tearing of the commissures and valves as well as for any changes in the aortic wall and calcified deposits. Then the aortic valve was replaced by a prosthesis. Several excised aortic valves were submitted to a histological examination. Those aortic leaflets were compared with calcified aortic valves that had not been dilated.

GROUP 2

Table 2 shows the clinical and haemodynamic data in

a group of 14 patients who had had percutaneous 




Commeau, Grollier, Lamy, Foucault, Durand, Maffei, Maiza, Khayat, Potie

Fig 1 Balloon catheter inflated through an aortic valve.

Table 1 Haemodynamic and anatomical data on patients in group 1

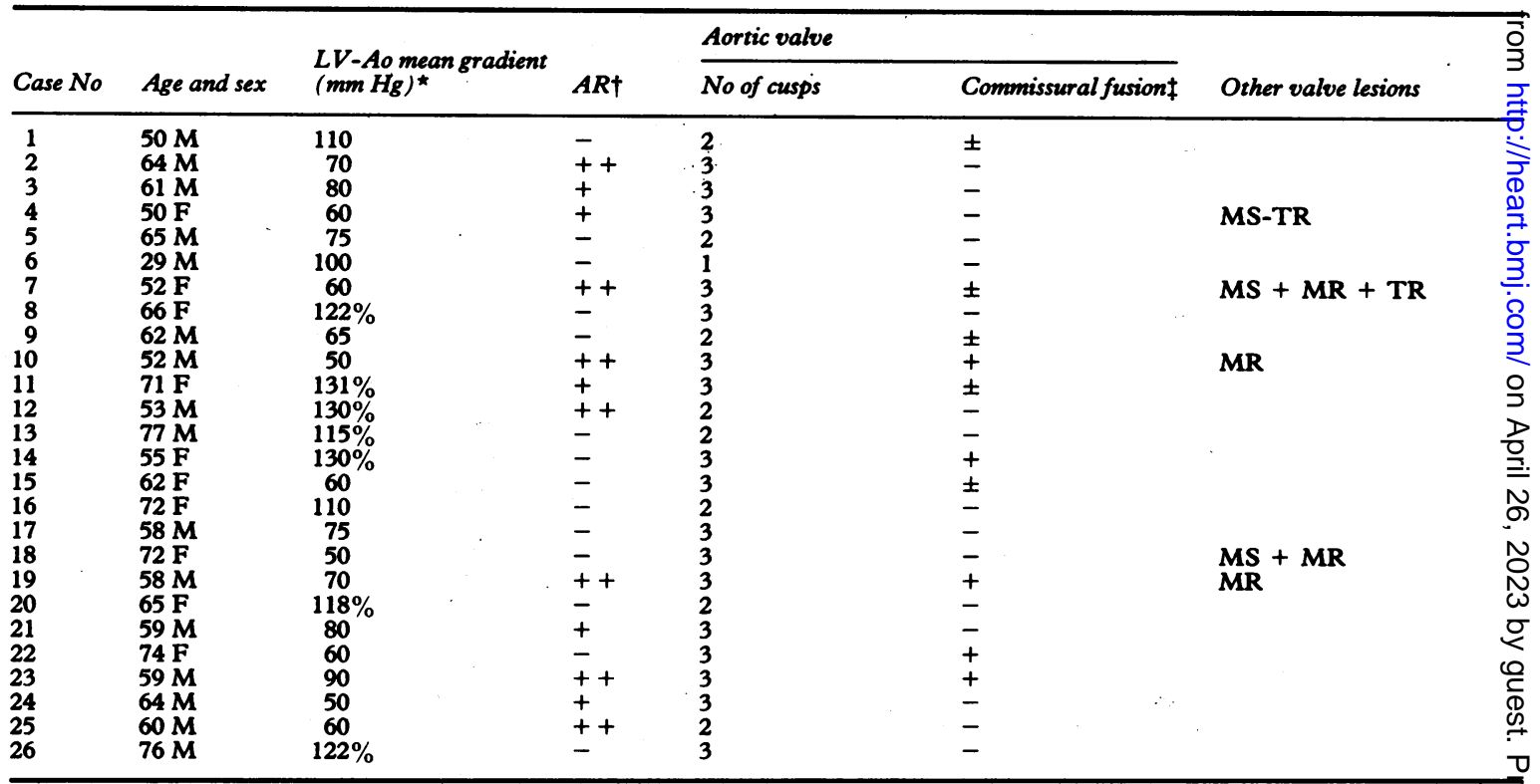

* Mean pressure gradient across the aortic valve. When the mean gradient was not measured the corrected left ventricular ejection time (\% $\%$ was calculated by Meiners method.

+- , No regurgitation; + , slight regurgitation; ++ , appreciable regurgitation.

$\mp-$, No fusion; \pm slight fusion; + considerable fusion.

$A R$, aortic regurgitation; $M R$, mitral regurgitation; $M S$, mitral stenosis; $T R$, tricuspid regurgitation. 
Table 2 Clinical and haemodynamic data on patients in group 2

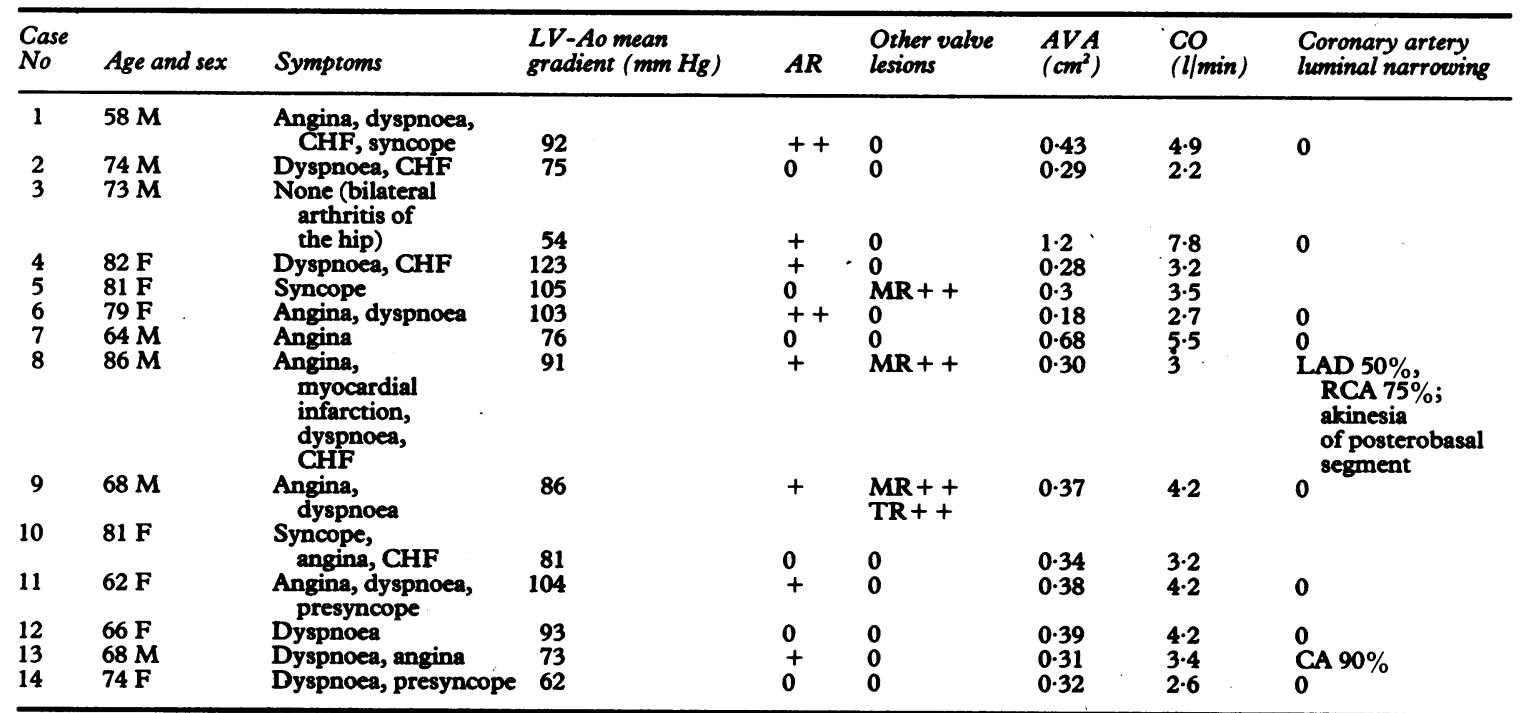

AVA, aortic valve area; CA, circumflex artery; CO, cardiac output; CHF, congestive heart failure; LAD, left anterior descending artery; RCA, right coronary artery. See footnote to table 1 for other abbreviations.

balloon dilatation of the aortic valve together with catheter studies. All had severe calcified aortic stenosis. In this group the patients preferred a percutaneous attempt to surgical valvar replacement or refused operation. If balloon dilatation was unsuccessful they were offered an aortic valve replacement. Patients gave their informed consent to these procedures.

\section{Cardiac catheterisation}

All patients were premedicated with $30 \mathrm{mg}$ of oral diazepam. Right and left sided catheterisation was carried out percutaneously. Right cardiac catheterisation was performed via the left femoral venous approach. In the left cardiac side a $8 \mathrm{Fr}$ pigtail catheter was advanced from the right femoral artery into the left ventricle and another $8 \mathrm{Fr}$ pigtail catheter was introduced through the left femoral artery and was placed in the aortic root to obtain simultaneous aortic and ventricular pressure recordings. Another left ventricular recording was obtained by the transseptal catheter technique with a 8.5 Fr Brockenbrough catheter inserted into the left ventricle through the right femoral vein. The mean aortic valve gradient during the systolic ejection period was obtained by planimetry with the Hewlett Packard catheterisation data analysis system. The mean gradients were calculated first by summing the pressure difference across the valve for each pressure reading obtained while the valve was open and also by dividing this sum by the number of pressure read- ings. Cardiac output was measured by the thermodilution technique (as the average of three concordant measurements) with a 7.5 Fr Swan-Ganz catheter inserted into the pulmonary artery through the left femoral vein. The aortic valve area was calculated by the Gorlin formula. In all cases coronary arteriography and left ventriculography were performed to assess the severity of coronary lesions and the myocardial function. Moreover, a cineangiogram was obtained of the aortic root and aortic and mitral regurgitation were assessed from 1 to $4+$ according to the Grossman criteria. ${ }^{12}$ None of our patients had mitral or aortic regurgitation of $3+$ or $4+$.

\section{Balloon dilatation}

The balloon catheter was percutaneously introduced into the right femoral artery on a long guide wire ( 300 cm long, 0.035 inches diameter); the flexible end was placed in the left ventricular apex to permit the exchange of the pigtail catheter inserted in the left ventricle with the balloon catheter. The balloon catheter was identical to the ones used in the peroperative procedure ( $9 \mathrm{Fr}$ Mansfield type catheter); diameters of the inflated balloon $(18-20 \mathrm{~mm})$ were chosen according to the size of the aortic valve annulus as assessed by echocardiography. In all cases only one balloon catheter was used. The balloon catheter was inserted through the aortic valve over the 0.035 inch guide wire that was looped in the left ventricle to stabilise the position of the balloon catheter which otherwise tends to move above or 


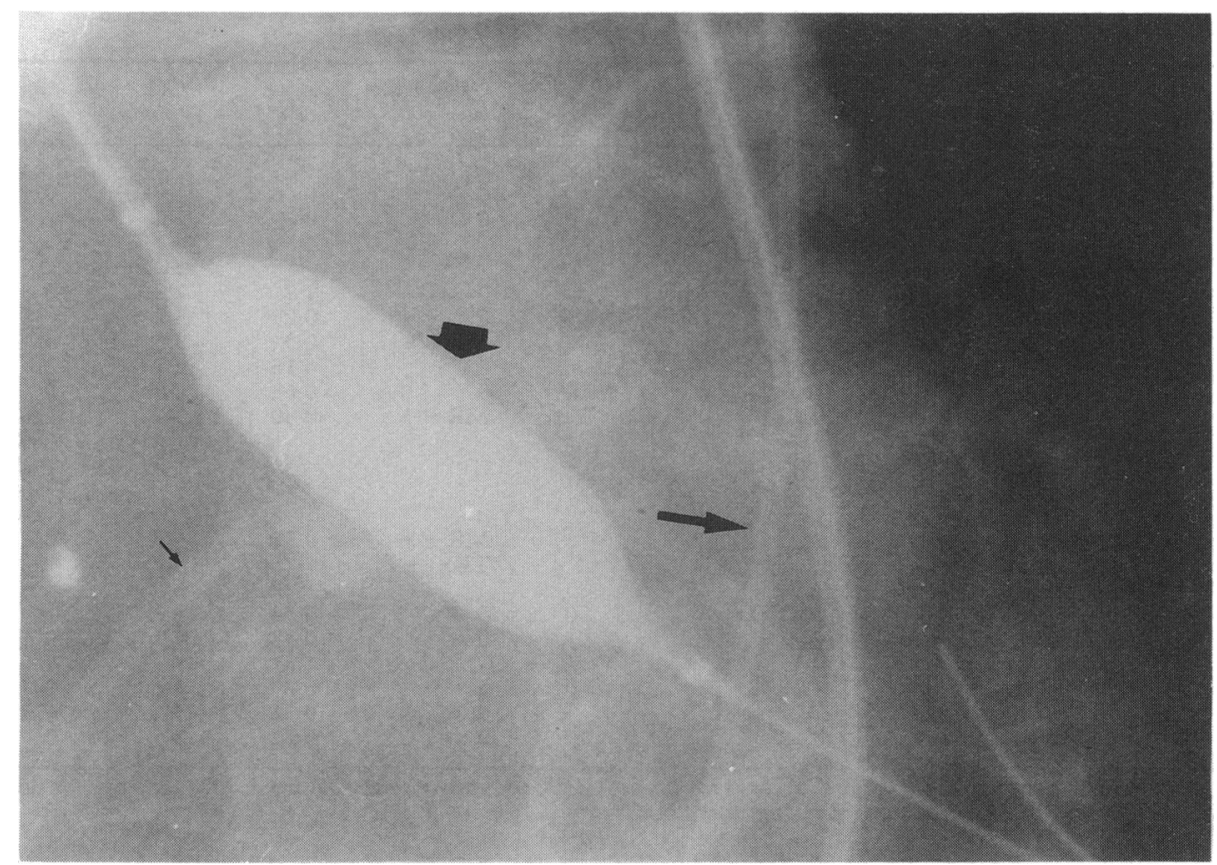

Fig 2 Cineangiogram of the procedure. The largest arrow shows balloon inflated through a calcified aortic valve; the pigtail catheter for monitoring aortic pressure is shown by the smaller arrow; and the Brockenbrough catheter for left ventricular monitoring is indicated by the smallest arrow.

below the aortic ring when it is inflated. The balloon catheter was inflated to pressures of 5-6 atm with a $50 \%$ mixture of saline solution and contrast medium after appropriate siting of the balloon had been confirmed by the appearance of a waist in the middle of the balloon (fig 2). The inflation-deflation cycle was varied according to the clinical and haemodynamic tolerance. Usually this cycle lasted less than 30 seconds but when the procedure was well tolerated inflation could last two or three minutes. During each inflation simultaneous aortic and ventricular pressures were continuously recorded; the number of inflations was varied according to the clinical tolerance and the decrease in the mean aortic gradient. At the end of the procedure the balloon catheter was withdrawn over the guide wire which was left in place. It was replaced by the pigtail catheter and the new mean aortic valve gradient and cardiac output were measured 20 minutes after the end of the procedure. A series of cineangiograms of the aortic root were examined for evidence of aortic regurgitation. The arterial and venous catheter were removed and haemostasis was achieved by direct compression. After the procedure, patients were monitored in the intensive care unit for one day. During the immediate recovery period 12 patients required a blood transfusion (2-4 units of packeç cells). The fall in haematocrit and haemoglobin concentration was not measured.

Haemodynamic follow up: eight days after the procedure a haemodynamic control was carried out through the same technique in the group where significant gradient decrease had been obtained. This delay was chosen to perform a haemodynamic controp. during the same hospital stay of our patients. In our group of 14 patients four had no control.

\section{Statistical analysis}

Group data are presented as mean (SD); the compar $\stackrel{2}{=}$ ison between the haemodynamic data before N immediately after, and eight days after the procedure were analysed for statistical significance by the Wilcoxon signed rank test used for paired samples $\omega$ Significance was tested by means of a $t$ table.

\section{Results}

GROUP 1 (TABLE 3)

In patients with minimal fusion of bicuspid of tricuspid valves only two had 1-2 mm tearing of the commissural fusion (fig 3). The leaflets, aorti\& annulus, aortic wall, and calcified deposits remaine 

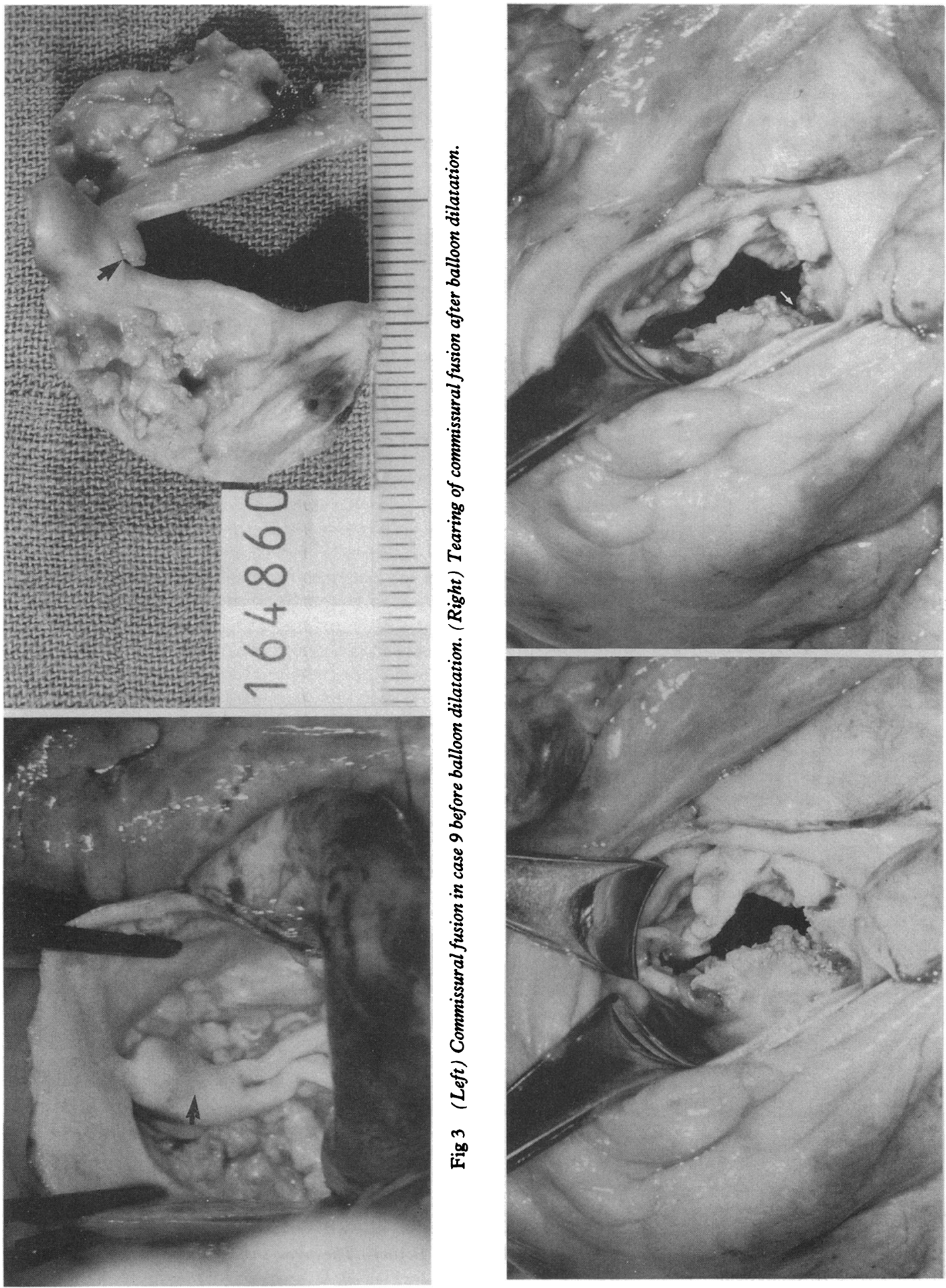

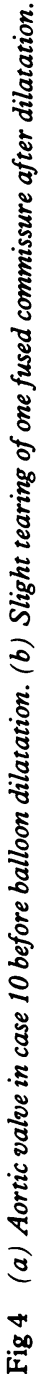



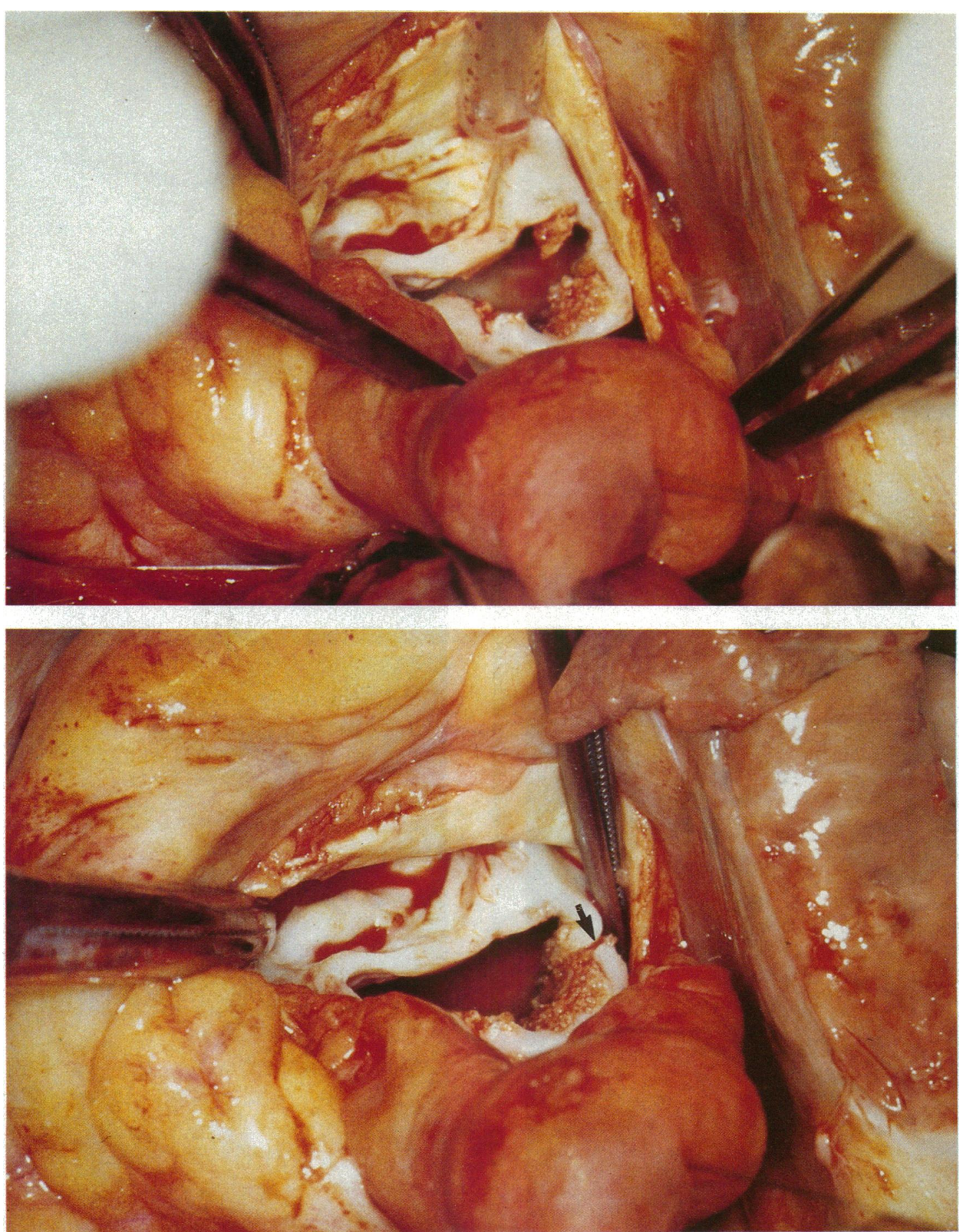

Fig 5 (Top) Aortic valve in case 19 before balloon dilatation. (Bottom) The arrow shows slight tearing of one fused commissure after dilatation. 


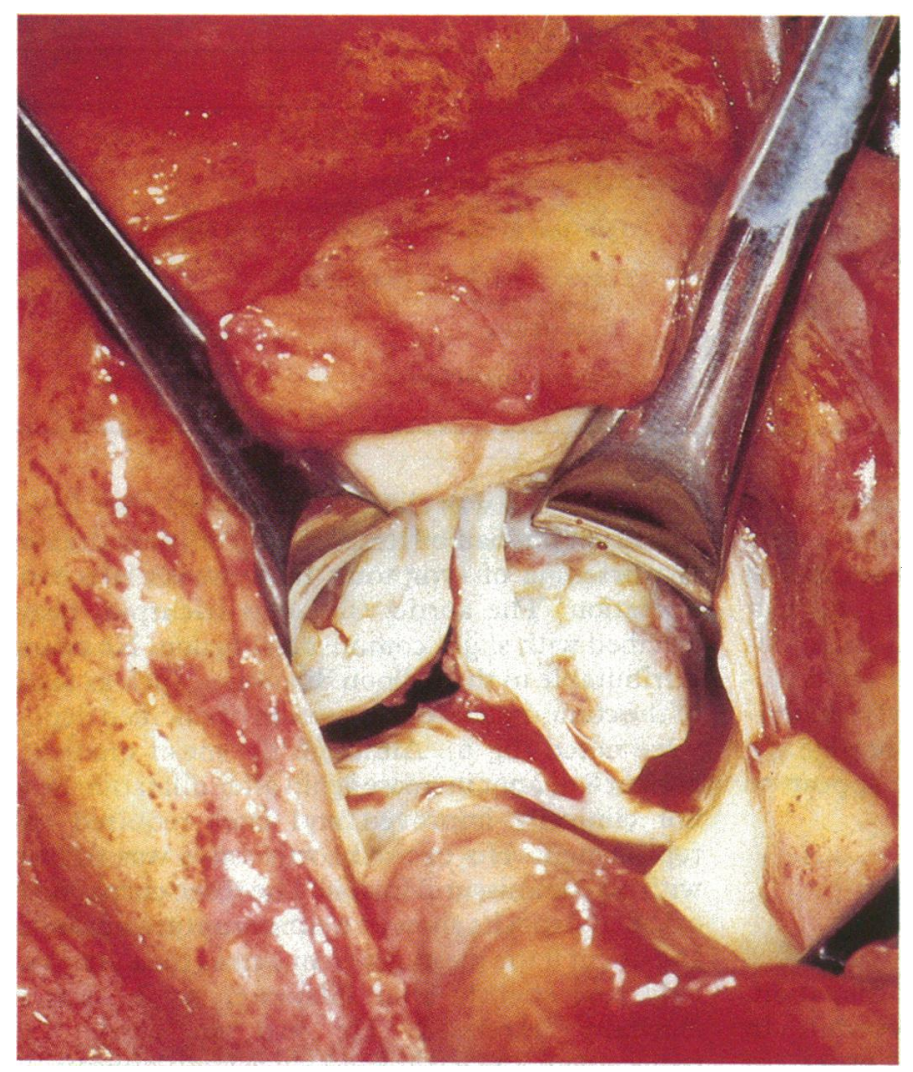

Fig 6 Peroperative view of the aortic valve of patient 4 (group 2).

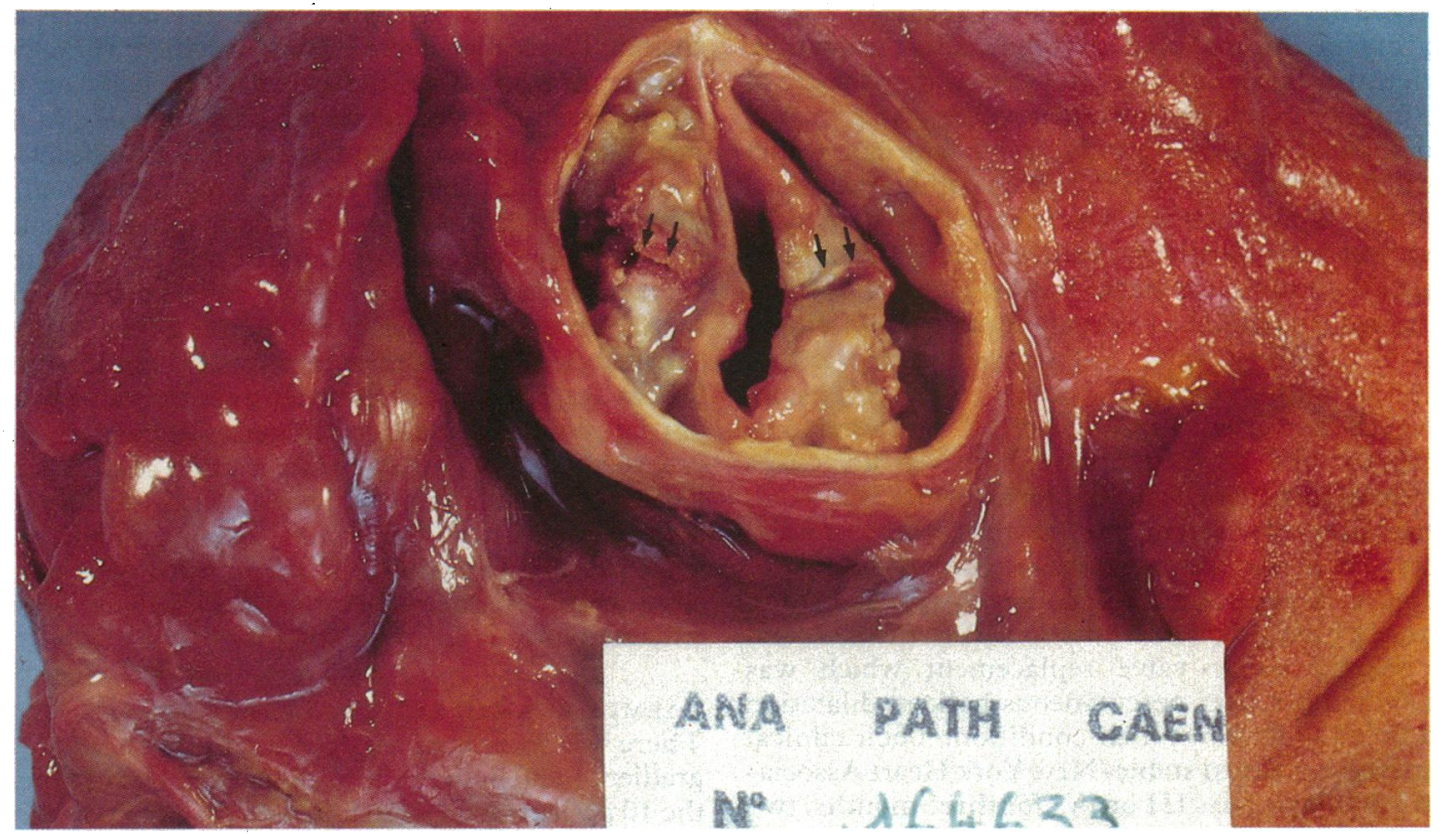

Fig 7 Bicuspid aortic valve with two fractures of calcified deposits (arrows). 
Table 3 Anatomical findings in group 1

\begin{tabular}{ll}
\hline Case No & Valve \\
\hline $\begin{array}{l}9 \\
\text { fig 3) }\end{array}$ & Bicuspid with moderate commissural fusion \\
10 & Tricuspid with pronounced bicommissural fusion \\
(fig 4) & Tricuspid with bicommissural fusion \\
14 & (one completely fused, other minimally fused) \\
15 & $\begin{array}{c}\text { Tricuspid with slight fusion } \\
\text { of one commissure }\end{array}$ \\
19 & $\begin{array}{c}\text { Tricuspid with considerable fusion } \\
\text { of three commissures }\end{array}$ \\
(fig 5) & $\begin{array}{c}\text { Tricuspid with complete fusion } \\
\text { of one commissure }\end{array}$ \\
\hline
\end{tabular}

Macroscopic changes

$2 \mathrm{~mm}$ tear in commissural fusion

$2 \mathrm{~mm}$ tear in commissural fusion (intercoronary cusp commissure)

$1 \mathrm{~mm}$ tear in the smallest commissural fusion

Complete tearing of commissural fusion $(2 \mathrm{~mm})$

Slight tearing

$\begin{array}{lc}\text { ricuspid with complete fusion } & \begin{array}{c}\text { Slight tearing of aortic } \\ \text { of one commissure }\end{array} \\ \text { annulus }\end{array}$

unchanged. In valves with more appreciable commissural fusion or an uncertain structure there were three instances of 1-2 mm tears of the commissural fusion (figs 4 and 5). In one case there was a $1 \mathrm{~mm}$ tear of the aortic ring. In the 20 other patients there was no evidence of any change. In one case the introduction of the balloon catheter through the valve mobilised the friable calcified deposits on the free edge of a hemi-valve. Balloon dilatation did not appear to change the valve rigidity.

\section{GROUP 2}

\section{Clinical follow up}

Four patients were not followed up after dilatation. Patient 5 died two days after the procedure in intractable cardiac failure after the onset of tachycardia despite an immediate decrease of $20 \mathrm{~mm}$ $\mathrm{Hg}$ of the mean valve gradient after dilatation. Patient 1 was operated on after the relative failure of the initial procedure; his aortic valve was tricuspid and showed neither commissural fusion nor leaflet tearing. Patient 3 refused follow up catheterisation; a bilateral hips operation was planned two months later but tachycardia prevented this. His haemodynamic condition is stable but his physical activity is limited. In patient 11 percutaneous balloon dilatation of the aortic valve was stopped after the first inflation caused syncope because of hypotension. When the aortic valve was replaced it was found to be tricuspid with a tricommissural fusion; the cusps were heavily calcified and the aortic orifice was fixed; there was neither tearing nor fracture of the commissures. These features suggested rheumatic disease of the valve. Ten patients had a follow up catheter study to assess haemodynamic function. Patients 2,7 , and 10 refused aortic valve replacement which was recommended after percutaneous balloon dilatation had failed to improve their condition. Their clinical condition remained stable (New York Heart Association functional class III or IV) for three months, two months, and one and a half months after the dilata- tion. Patient 4 was clinically improved after balloon dilatation but had bilateral pleural effusion drainage. N A worsening of symptoms three weeks later led tog operation. The aortic valve was tricuspid, heavilycalcified with slight commissural fusion. No changes attributable to the balloon dilatation, such as tearing of the commissures or disruption of calcified depositso were noted (fig 6). Although the mean gradient in $\mathcal{F}$ patient 8 did not increase again after dilatation he was $\overrightarrow{0}$ not clinically improved and later required valve $\infty_{\infty}^{\circ}$ replacement. His excised aortic valve was tricuspid with no commissural fusion. The three cusps and the calcified deposits showed neither rupture nor injury. In patient 9 the mean gradient across the aortic valvea only rose slightly after dilatation but he was noto clinically improved. He had an aortic valve replacement and a tricuspid valve annuloplasty. The aortic valve was tricuspid with no commissural fusion. The leaflets were heavily calcified; there was no fracture of either the calcified deposits or the cusps. Despite a final decrease of $25 \mathrm{~mm} \mathrm{Hg}$ in theo mean aortic gradient patient 6 died of refractory? congestive heart failure one and a half months aftero dilatation. Necropsy showed major left ventricular:hypertrophy and a bicuspid aortic valve (fig 7); this@ valve was rigid and with heavy calcification of the raphe. On each commissure there was a large broken? calcified deposit. Each fracture was $0.5 \mathrm{~cm}$ long and $0.3 \mathrm{~cm}$ deep. In spite of these changes the valve could? not be mobilised with the fingers. Stenosis in thisN case seemed to be caused by the rigidity of the cusps. Patient 14 had only a two week clinical follow up: dyspnoea lessened; the control mean gradient was $\omega$ less than $40 \mathrm{~mm} \mathrm{Hg}$ but the aortic value orifice was? considerably reduced because the cardiac outpute remained low.

HAEMODYNAMIC RESULTS (TABLE 4)

There was an immediate decrease in the mean aortie्ष gradient in all patients after dilatation, but in nine of the 10 patients who were followed up eight days late this gradient subsequently increased. In two caseo 
Table 4 Haemodynamic results in group 2

\begin{tabular}{|c|c|c|c|c|c|c|c|c|c|}
\hline \multirow[b]{2}{*}{ Case No } & \multicolumn{3}{|l|}{ Before } & \multicolumn{3}{|l|}{ After } & \multicolumn{3}{|c|}{8 days after } \\
\hline & $\begin{array}{l}L V-A o \\
(m m H g)\end{array}$ & $\begin{array}{l}A V A \\
\left(\mathrm{~cm}^{2}\right)\end{array}$ & $\begin{array}{l}C O \\
(l / \min )\end{array}$ & $\begin{array}{l}L V-A o \\
(m m H g)\end{array}$ & $\begin{array}{l}A V A \\
\left(\mathrm{~cm}^{2}\right)\end{array}$ & $\begin{array}{l}C O \\
(l / \min )\end{array}$ & $\begin{array}{l}L V-A o \\
(m m H g)\end{array}$ & $\begin{array}{c}A V A \\
\left(\mathrm{~cm}^{2}\right)\end{array}$ & $\begin{array}{l}C O \\
(l / \min )\end{array}$ \\
\hline $\begin{array}{r}1 \\
2 \\
3 \\
4 \\
5 \\
6 \\
7 \\
8 \\
9 \\
10 \\
11 \\
12 \\
13 \\
14\end{array}$ & $\begin{array}{r}92 \\
75 \\
54 \\
123 \\
105 \\
103 \\
76 \\
91 \\
86 \\
81 \\
104 \\
93 \\
73 \\
62\end{array}$ & $\begin{array}{l}0.43 \\
0 \cdot 29 \\
1 \cdot 20 \\
0 \cdot 28 \\
0 \cdot 30 \\
0 \cdot 18 \\
0 \cdot 68 \\
0 \cdot 30 \\
0 \cdot 37 \\
0 \cdot 34 \\
0 \cdot 38 \\
0 \cdot 39 \\
0.31 \\
0.32\end{array}$ & $\begin{array}{l}4 \cdot 9 \\
2 \cdot 2 \\
7 \cdot 8 \\
3 \cdot 2 \\
3 \cdot 5 \\
2 \cdot 7 \\
5 \cdot 5 \\
3 \cdot 0 \\
4 \cdot 2 \\
3 \cdot 2 \\
4 \cdot 2 \\
4 \cdot 2 \\
3 \cdot 4 \\
2 \cdot 6\end{array}$ & $\begin{array}{r}89 \\
35 \\
31 \\
56 \\
86 \\
53 \\
45 \\
76 \\
45 \\
5 \\
97 \\
39 \\
44 \\
36\end{array}$ & $\begin{array}{l}0.44 \\
0.51 \\
1.50 \\
0.41 \\
0.38 \\
0.21 \\
0.80 \\
0.35 \\
0.71 \\
1.53 \\
0.31 \\
0.63 \\
0.41 \\
0.25\end{array}$ & $\begin{array}{l}4.9 \\
1.9 \\
7.9 \\
3.0 \\
3.5 \\
1.9 \\
4.8 \\
3.2 \\
4.5 \\
3.6 \\
4.1 \\
3.2 \\
2.7 \\
1.3\end{array}$ & $\begin{array}{r}76 \\
112 \\
78 \\
56 \\
73 \\
74 \\
60\end{array}$ & $\begin{array}{l}0.31 \\
0.27 \\
\\
0.25 \\
0.78 \\
0.48 \\
0.38 \\
0.47\end{array}$ & $\begin{array}{l}2 \cdot 7 \\
3 \cdot 1 \\
\\
3 \cdot 2 \\
5 \cdot 7 \\
4 \cdot 1 \\
3 \cdot 8 \\
3 \cdot 8\end{array}$ \\
\hline
\end{tabular}

this increase was slight (fig 8). In 11 patients there was an increase in the area of the aortic valve orifice immediately after dilatation. In seven of the 10 patients who were followed up the area had decreased (fig 9). Immediately after balloon dilatation the mean aortic gradient fell significantly $(p<0.01)$ and the aortic valve area increased significantly $(p<0.01)$ but eight days after dilatation the mean gradient had risen and the aortic valve area had become smaller. Nevertheless, the difference between the initial and follow up gradients was significant $(p<0.01)$, as was the difference between aortic valve areas $(p<0.05)$. The gradient across the aortic valve increased significantly in the eight days after dilatation $(p<0.01)$ but there was no significant change in cardiac output (table 5). Moreover, in one patient who had aortic

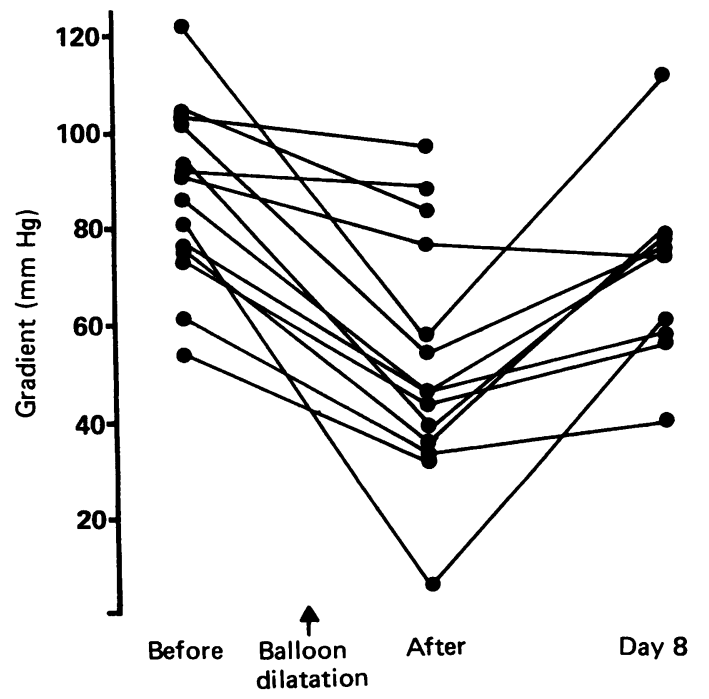

Fig 8 Changes in aortic mean gradient immediately after dilatation and eight days later. regurgitation before dilatation cineangiograms obtained after the procedure showed an increase in regurgitation (from $1+$ to $2+$ ). Patients without aortic regurgitation did not have regurgitation after the procedure.

The Gorlin formula ${ }^{13}$ does not always give an accurate approximation of the actual valve area. This formula considers a fixed valve area and a steady blood flow. Moreover, empirical constants are used. Further error was introduced in the original formula by assuming that the left ventricular mean diastolic pressure was $5 \mathrm{~mm} \mathrm{Hg}$. Also the large variations in

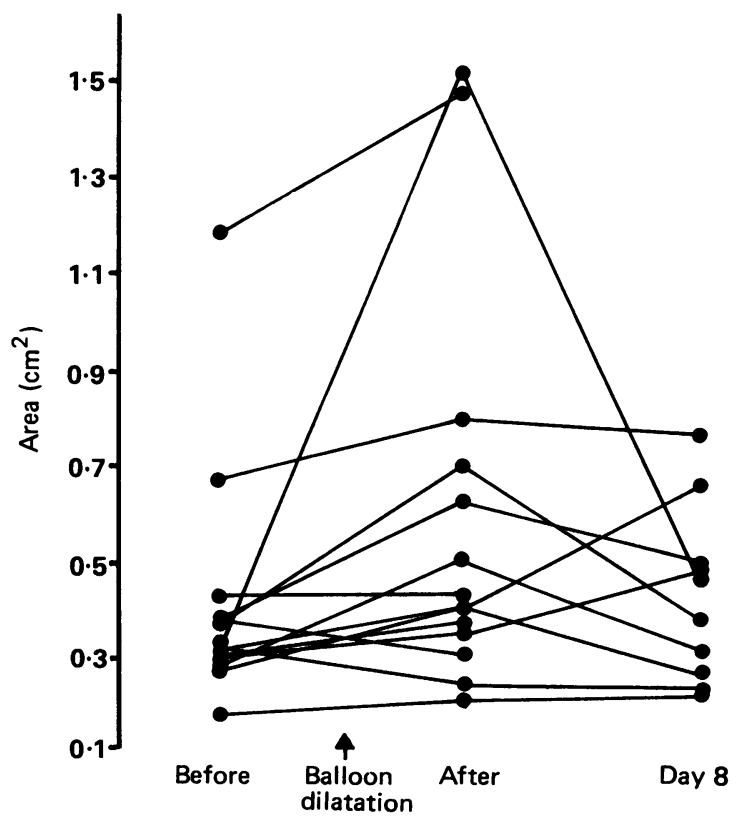

Fig 9 Changes in aortic valve area immediately after dilatation and eight days later. 
Table 5 Statistical analysis of haemodynamic results in group 2

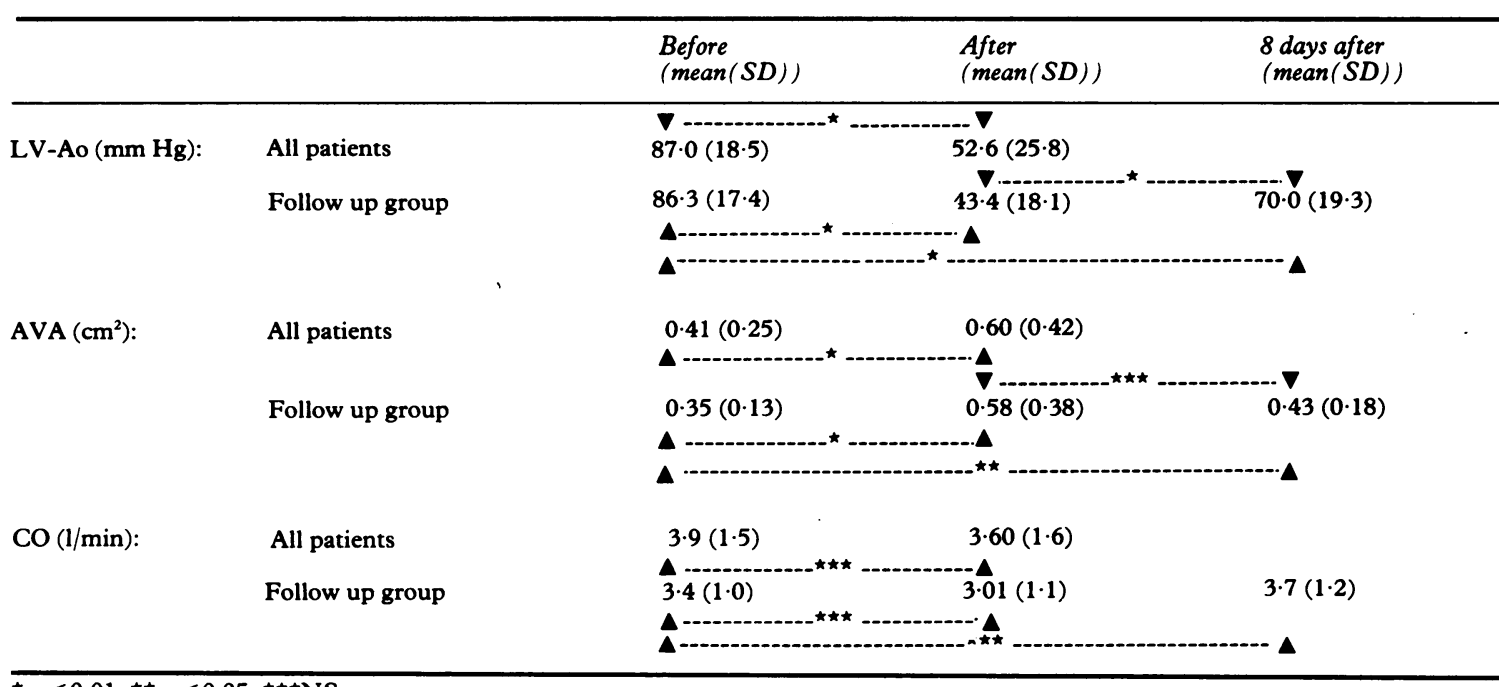

${ }^{\star} \mathrm{p} \leqslant 0.01 ;{ }^{\star \star} \mathrm{p} \leqslant 0.05 ;{ }^{\star \star \star} \mathrm{NS}$.

See footnote to tables 1 and 2 for abbreviations.

flow pattern across the calcified aortic valve may alter the relation between the orifice area and pressure gradient. Therefore, estimation of valve areas, particularly at low flow rates, may be incorrect and should be regarded as measurements of functional size.

\section{HISTOLOGICAL FINDINGS}

A pathologist examined the aortic valves from two patients (cases 6 and 9). Patient 6 had an unicommissural valve that was $3 \mathrm{~cm}$ diameter and $0.7 \mathrm{~cm}$ thick.
It was irregularly thickened and rigid with important calcified deposits over the whole valve (leaflets, free edge, annulus). The valve was composed of fibrous, dense, acellular, sometimes hyaline tissue and included calcified deposits of unequal sizes, frequen-

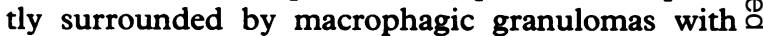
some giant cells. The endothelium was histologically $\overrightarrow{\overrightarrow{0}}$ unchanged. There were no macroscopic or his- 3 tological changes attributable to balloon dilatation. Patient 9 had a bicuspid valve that was $3.5 \mathrm{~cm}$ along its longest axis, $2.4 \mathrm{~cm}$ along its shortest axis, and 0.5

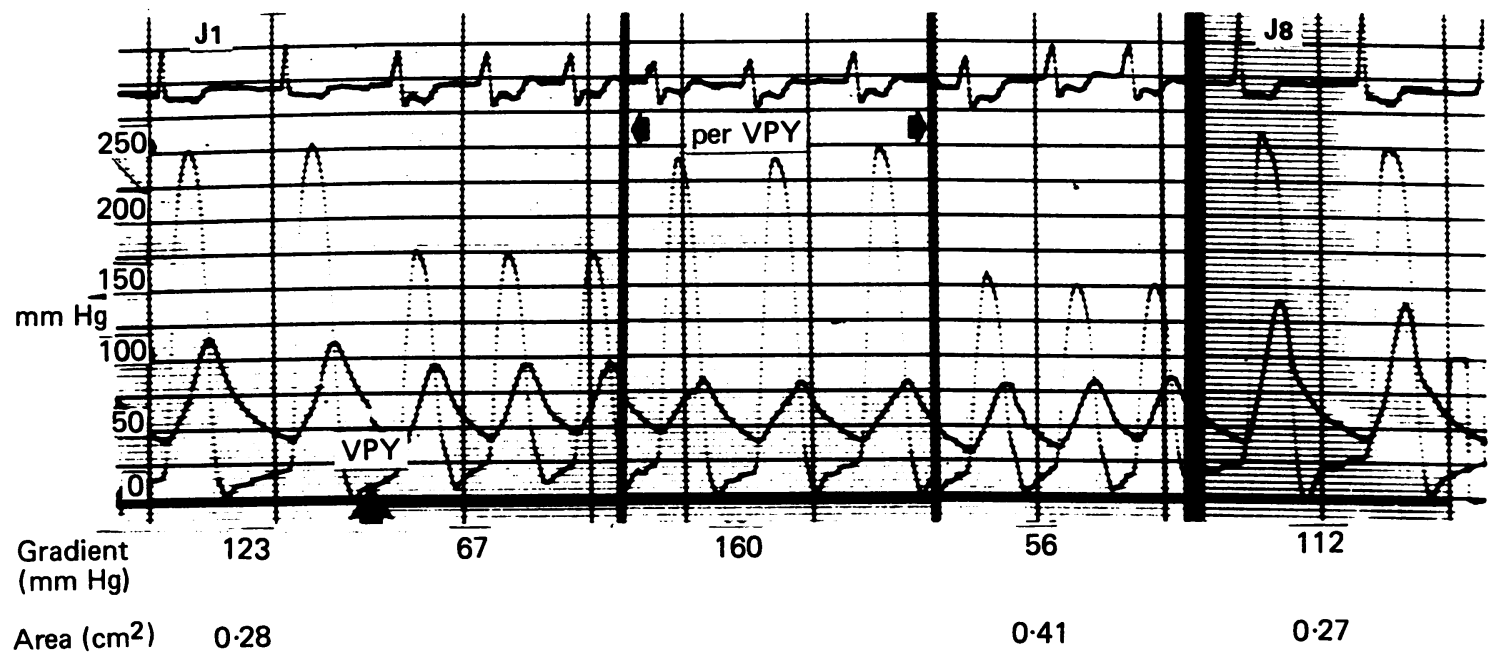

Fig 10 Simultaneous recording of left ventricular and aortic pressures before, during, and after balloon dilatation in case 4 (group 2). There were ischaemic changes on the electrocardiogram and the mean gradient pressure increased during dilatation. 


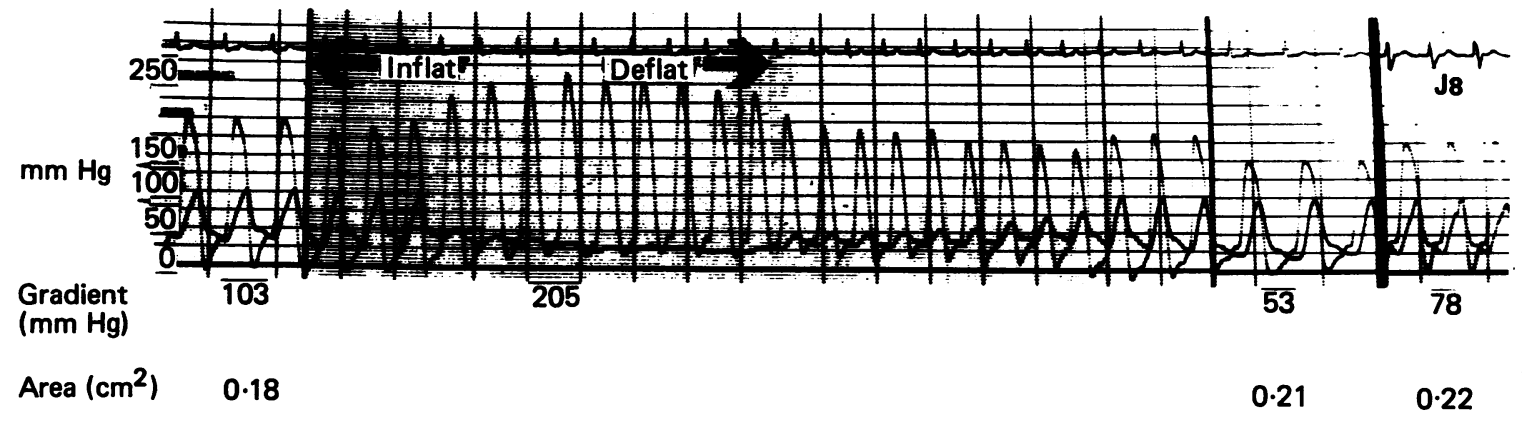

Fig 11 Simultaneous recording of left ventricular and aortic pressures before, during, and after ballon dilatation in case 6 (group 2). There was a considerable increase in mean gradient pressure during dilatation.

cm deep. The valve structures were heavily and irregularly calcified. The commissures and free wall were thickened and rigid but the fusion was minimal and measured $1 \mathrm{~cm}$ on its anterior tip. This fusion was torn for $2 \mathrm{~mm}$, probably by the balloon dilatation. The valve was made up of fibrous and hyaline tissue and contained few vessels. There were irregular calcified bodies that did not contain macrophages. No histological or macroscopic abnormalities that were attributable to the balloon dilatation were seen.

The pathogist also examined the aortic valve from patient 6 in group 2 . The valve structures were thickened by dense and hyaline fibrosis and a large calcified mass, which in places showed osteoid metaplasis. Apart from the two splits described above, fissure and splitting caused by balloon dilatation were not seen.

\section{Discussion}

Like other workers we found that most elderly patients with calcified stenosis of the aortic valves have either tricuspid aortic valves with no or few commissural fusions (Monckeberg disease) or bicuspid valves. ${ }^{14-16}$ The stenosis and the haemodynamic gradient were more the result of rigid, stiff aortic valves with heavily calcified cusps than of a fixed anatomical stenosis caused by commissural fusion. We found that inflation of the balloon during dilatation raised the aortic cusps because of the pressure exerted on the endoventricular side of the cusps. We saw no fracturing or tearing of calcified deposits. During deflation of the balloon the aortic cusps returned to their initial position with no apparent change in their rigidity. In cases in which the structure of the valve was uncertain and there was commissural fusion balloon inflation did produce a slight tearing. But in our opinion this could not account for any benefit or long term success. Balloon dilatation is also unlikely to tear the aortic annulus.
In this group there were no appreciable macroscopic changes to the aortic valves, more specifically we did not see fissuring or fragmentation of the calcified deposits.

Although there was a real and significant fall in mean aortic gradient immediately after balloon dilatation, this did not persist and eight days after the procedure, despite a significant decrease in the mean aortic gradient and significant increase of the valve area when compared with the valves before dilatation, the haemodynamic valves remained within the range for severe aortic stenosis.

We believe that the immediate fall and secondary rise in the mean aortic gradients are explained by the important blood loss associated with the procedure and also arrhythmia and transient ischaemia that occur during the procedure. Twelve of our patients required transfusion in the immediate recovery period. These postcharge increase and myocardial ischaemia (secondary to the partial occlusion of the coronary ostia by the calcific aortic leaflets during the balloon inflation) are performed on hypertrophic and failing hearts.

We believe that the indication most favourable for percutaneous aortic dilatation is stenosis caused by symmetrical commissural fusion of a tricuspid uncalcified valve such as that associated with rheumatic disease. None of our patients, however, had valves like this, and aortic stenosis in elderly patients is rarely caused by rheumatic disease. ${ }^{14}$ Furthermore, $90 \%$ of elderly patients with pure aortic stenosis have a tricuspid valve; $\leqslant 30 \%$ have fusion of one or two of the commissures and fusion of all three commissures is exceptional.

We believe that percutaneous balloon dilatation of the aortic valve in elderly patients is seldom helpful. But any benefit of the procedure in elderly patients with severe aortic stenosis can only be assessed by clinical follow up and multicentre short term and long term studies of haemodynamic function and morbidity and mortality. 


\section{References}

1 Van Andel GJ, Van Erp WF, Krepel VM, Breslan PJ. Percutaneous transluminal dilatation of the iliac artery: long-term results. Radiology 1985;156:321-3.

2 Martin LG, Price RB, Casarella WJ, et al. Percutaneous angioplasty in clinical management of reno-vascular hypertension. Initial and long-term results. Radiology 1985;155:629-33.

3 Gruentzig AR. Percutaneous transluminal coronary angioplasty: six years' experience. Am Heart J 1984;107:818-9.

4 Motarjem A, Keifer JW, Zurska AJ. Percutaneous transluminal angioplasty of the brachiocephalic arteries. Am J Roentgenol 1982;138:457-62.

5 Lababidi Z, Wu JR. Percutaneous balloon pulmonary valvuloplasty. Am J Cardiol 1983;52:560-2.

6 Rupprath G, Neuhaus KL. Percutaneous balloon valvuloplasty for aortic valve stenosis in infancy. $\mathrm{Am} \mathrm{J}$ Cardiol 1985;55:1655-6.

7 Inoue $\mathrm{K}$, Owaki T, Nakamura T, Kitamura F, Miyamoto N. Clinical application of transvenous mitral commissurotomy by a new balloon catheter. $J$ Thorac Cardiovasc Surg 1984;87:394-402.

8 McKay RG, Lock JE, Keane JF, Safian RD, Aroesty JM, Grossman W. Percutaneous mitral valvuloplasty in an adult patient with calcific rheumatic mitral stenosis. J Am Coll Cardiol 1986;7:1410-5.
9 Palacios IF, Lock JE, Keane JF, Block PC. Percutan $\stackrel{C}{-}$ eous transvenous balloon valvotomy in a patient with severe calcific mitral stenosis. J Am Coll Cardio fo 1986;7:1416-9.

10 Cribier A, Saoudi N, Berland J, Savin T, Rocha P $\overline{\bar{x}}$. Letac B. Percutaneous transluminal valvuloplasty of acquired aortic stenosis in elderly patients: an alter- -2 native to valve replacement? Lancet 1986;i:63-7.

11 McKay RG, Safian RD, Lock JE, et al. Balloondilatation of calcific aortic stenosis in elderly patients: postmortem, intraoperative, and percutaneous valvuloplasty studies. Circulation 1986;74:119-25.

12 Grossman W. Catheterization and angiography Philadelphia: Lea and Febiger, 1980:310-5.

13 Gorlin R, Gorlin SG. Hydraulic formula for calculatione of the area of the stenotic mitral valve, other cardiac valves and central circulatory shunts. Am Heart N 1951;41:1-29.

14 Roberts WC. Anatomically isolated aortic valvularo disease. The case against its being of rheumatic etiology. Am J Med 1970;49:151-9.

15 Roberts WC. The structure of the aortic valve in clinically isolated aortic stenosis. An autopsy study of 162 patients over 15 years of age. Circulationz 1970;42:91-7.

16 Roberts WC, Perloff JK, Costantino T. Severe valvularo aortic stenosis in patients over 65 years of age. $\mathrm{A}^{\mathrm{O}}$ clinicopathologic study. Am J Cardiol 1971;27:497506. 